\title{
Kajian Pembelajaran Baca Tulis Al-Qur'an
}

\author{
Muhammad Aman Ma'mun \\ Dosen Sekolah Tinggi Ilmu Tarbiyah Al Urwatul Wutsqo Jombang, Indonesia \\ Email: mamanmamun3@gmail.com
}

\begin{abstract}
Preferably the human is the one who learns the Qur'an and teach it. So learning to read the Qur'an to be conducted early as the provision of life and afterlife. Learning the Quran as an interaction learning activities also have a purpose. The purpose of learning the Qur'an is as follows: 1) so that students can read Quran fluently and correctly according to the recitation. 2) so students can familiarize the Qur'an in his life. 3) enrich the vocabulary words and sentences that are beautiful and interesting. In Indonesia there are various methods of reading the Qur'an as may have been collected by the LITBANG in 1994. A variety of methods have advantages and disadvantages of each. One method is to write the Qur'an by dictation. There are four (4) types of dictation that can be applied to a person according to their cognitive level: Imla' manqu, Imla 'mandhur, Imla' ghairu al-mandhur (masmu'), Imla' ikhtibari.
\end{abstract}

Keywords: Learning, Methods, Reading, Writing, Al-Qur'an 
Sebaik-baiknya manusia adalah orang yang belajar al-Qur'an dan mengajarkannya. AlQur'an sebagai pedoman kehidupan umat Islam tiada alasan untuk tidak membacanya, baik di waktu sempit maupun luang, baik tua maupun muda, baik besar maupun kecil. Maka pembelajaran baca al-Qur'an mutlak dilakukan sejak dini sebagai bekal kehidupan di dunia dan akhiratnya. Namun bagaimana cara mengajarkan membaca alQur'an.

Pembelajaran cara membaca AlQur'an perlu di lakukan sejak dini secara terus menerus oleh umat islam agar dapat mengembangkan diri secara sistematis dan menjalani hidup sesuai aturan dengan AlQur'an sebagai pedoman hidupnya. Sehingga dapat menciptakan manusia dengan akhlak yang baik. Pembelajaran membaca Al-Qur'an biasanya dilakukan pertama kali saat anak berusia 2 tahun atau saat anak sudah dapat berbicara dengan lebih jelas. Pembelajaran membaca AlQur'an bagi anak-anak biasanya dilakukan di rumah dengan orangtua sebagai pembimbing atau di madrasah dengan dibimbing oleh ustadz atau guru mengaji yang sudah ahli. Tetapi terkadang belajar membaca Al-Qur'an di madrasah tidak selalu dapat dilakukan, karena masalah cuaca serta guru mengajinya tidak dapat hadir. Anak juga terkadang malas untuk melakukan hal lain selain bermain.

Pembelajaran Baca Qur'an adalah pembelajaran yang sangat penting bagi seluruh umat Islam, karena membaca alQur'an adalah gerbang menuju pengetahuan Islamiah seperti akidah, ibadah, akhlak dan sebagainya. Proses baca ini adalah proses pertama dan utama dalam membuka kunci petunjuk umat Islam tersebut, sebagaimana wahyu yang pertama turun dari Allah kepada umat manusia melalui Nabi Muhammad SAW yaitu:

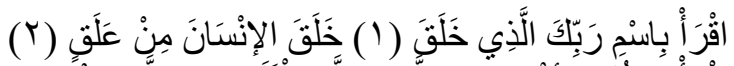

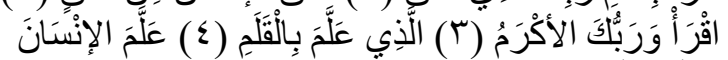

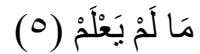

"Bacalah dengan (menyebut) nama Tuhanmu yang Menciptakan. Dia telah menciptakan manusia dari segumpal darah. Bacalah, dan Tuhanmulah yang Maha pemurah. yang mengajar (manusia) dengan perantaran kalam. Dia mengajar kepada manusia apa yang tidak diketahuinya." (QS; al-‘Alaq : 1-5)

Metode penyampaian wahyu yang pertama dari malaikat Jibril kepada Nabi Muhammad ini merupakan metode pembelajaran baca al-Qur'an yang pertama. Maka setiap diturunkannya alQur'an, maka Nabi langsung menyampaikan kepada para sahabat, di mana sahabat pada waktu itu masih banyak yang belum bisa membaca apalagi menulis namun sahabat dapat menerima bacaan alQur'an dengan baik. Malaikat Jibril ketika menyampaikan wahyu yang pertama kepada Nabi dengan perintah membaca sampai mengulang tiga kali menjadi metode Nabi dalam mengajar atau menyampaikannya kepada sahabat.

Nabi Muhammad Rasulullah tiada henti-hentinya memerintahkan kepada sahabat untuk selalu membaca firman Allah yang menjadi pedoman umat Islam ini dan meminta agar sahabat mengajarkannya kepada sahabat lainnya, tabiin, tabiittabiin hingga sampai pada generasi kita sekarang ini. Berbagai metode pengajaran al-Qur'an telah diterapkan sepanjang sejarah keislaman dari zaman ke zaman, baik yang secara tradisional (belum terstruktur) maupun yang sudah terstruktur.

\section{Pembahasan}

\section{a. Pembelajaran Al-Qur'an}

\begin{tabular}{llr}
\multicolumn{2}{c}{ Belajar dan } & \multicolumn{2}{c}{ pembelajaran } \\
merupakan dua konsep yang saling & \multicolumn{2}{c}{ yang } \\
berkaitan. Konsep belajar berakar pada
\end{tabular}


pihak siswa dan konsep pembelajaran berakar pada pihak guru dan keduanya bisa berdiri sendiri dan juga menyatu, bergantung kepada situasi dari kedua kegiatan itu terjadi.

Pembelajaran adalah proses interaksi peserta didik dengan pendidik dan sumber belajar pada suatu lingkungan belajar. Pembelajaran merupakan bantuan yang diberikan pendidik agar dapat terjadi proses perolehan ilmu dan pengetahuan, penguasaan kemahiran dan tabiat, serta pembentukan sikap dan kepercayaan pada peserta didik. Dengan kata lain, pembelajaran adalah proses untuk membantu peserta didik agar dapat belajar dengan baik.(Wikepedia, 2016)

Di sisi lain pembelajaran mempunyai pengertian yang mirip dengan pengajaran, tetapi sebenarnya mempunyai konotasi yang berbeda. Dalam konteks pendidikan, guru mengajar agar peserta didik dapat belajar dan menguasai isi pelajaran hingga mencapai sesuatu objektif yang ditentukan (aspek kognitif), juga dapat memengaruhi perubahan sikap (aspek afektif), serta keterampilan (aspek psikomotor) seorang peserta didik, namun proses pengajaran ini memberi kesan hanya sebagai pekerjaan satu pihak, yaitu pekerjaan pengajar saja. Sedangkan pembelajaran menyiratkan adanya interaksi antara pengajar dengan peserta didik.

Menurut Hilgard dan Marquis yang dikutip oleh Aminudin Rasyad learning is the process by which an activity originates or is changed through training procedure (whether in the laboratory or in natural environment) as distringuished from changes by factor not attributable to training. Menurut Hilgart dan Marquis belajar merupakan proses mencari ilmu yang terjadi dalam diri seseorang melalui latihan, pembelajaran dan sebagainya, sehingga terjadi perubahan dalam diri. (Rasyad, 2003)

Muhibbin Syah memaparkan "Belajar pada dasarnya adalah tahapan perubahan perilaku siswa yang relatif positif dan menetap sebagi hasil interaksi dengan lingkungan yang melibatkan proses kognitif."(Syah, 2005) Sedangkan dalam Kamus Bahasa Indonesia, pembelajaran adalah "proses, cara, perbuatan menjadikan orang atau makhluk hidup belajar."(Depdikbud, 1989) UU SISDIKNAS nomor 20 tahun 2003 menerangkan bahwa pembelajaran adalah "proses interaksi peserta didik dengan pendidik dan sumber belajar pada suatu lingkungan belajar." Beberapa pendapat mengenai pengertian pembelajaran, diantaranya menurut Tohirin pembelajaran merupakan upaya membelajarkan atau upaya mengarahkan aktivitas siswa kearah aktivitas belajar.(Tohirin, 2006)

Aminuddin Rasyad mendefinisikan pembelajaran adalah "proses yang terjadi yang membuat seseorang atau sejumlah orang yaitu siswa melakukan proses belajar sesuai dengan rencana pengajaran yang telah diprogramkan.'(Rasyad, 2003) Sedangkan menurut Oemar Hamalik pembelajaran adalah "suatu kombinasi yang tersusun meliputi unsur-unsur manusiawi, material, fasilitas, perlengkapan, dan prosedur yang saling mempengaruhi untuk mencapai tujuan pembelajaran."(Hamalik, 1999)

Menurut Sujana, pembelajaran adalah setiap upaya yang sistematik dan disengaja oleh pendidik untuk menciptakan kondisi-kondisi agar peserta didik melakukan kegiatan mengajar.(Sudjana, 2001) Pembelajaran juga dapat diartikan dengan proses untuk membantu peserta didik agar dapat belajar dengan baik. Pembelajaran yang berkualitas sangat tergantung dari motivasi pelajar dan kreatifitas pengajar. Pembelajar yang memiliki motivasi tinggi ditunjang dengan pengajar yang mampu memfasilitasi motivasi tersebut akan membawa pada keberhasilan pencapaian target belajar. Target belajar dapat diukur melalui perubahan sikap dan kemampuan siswa 
melalui proses belajar. Desain pembelajaran yang baik, ditunjang fasilitas yang memandai, ditambah dengan kreatifitas guru akan membuat peserta didik lebih mudah mencapai target belajar.(Sardiman, 2008)

Dari pengertian diatas dapat diambil kesimpulan, yang dimaksud dengan pembelajaran adalah suatu aktivitas atau proses yang mengarahkan siswa melakukan proses belajar, dengan melibatkan unsur-unsur manusiawi, material, fasilitas, perlengkapan, dan prosedur yang saling mempengaruhi untuk mencapai tujuan pembelajaran.

Lafal Al-Qur'an secara bahasa sama dengan qira'ah, yaitu akar kata dari qara'a, qira'atan wa qur'anan, ia merupakan bentuk mashdar menurut wazan dari kata fu'lan, seperti qufran dan syukron. Bentuk kata kerjanya adalah qara'a yang berarti mengumpulkan dan menghimpun.(Manna', 2006) Dengan demikian lafal Qur'an dan qira'ah secara bahasa berarti menghimpun dan memadukan sebagian huruf- huruf dan kata-kata dengan sebagian lainnya.

Pengertian Al-Qur'an menurut Hasbi Ash Shidieqy adalah "wahyu Ilahi yang diturunkan kepada Muhammad SAW, yang telah disampaikan kepada kita ummatnya dengan jalan mutawattir, yang dihukum kafir orang yang mengingkarinya.(M.Hasby, 1997)" Sedangkan menurut Subhi As-Shalih AlQur'an adalah 'kalam Ilahi yang diturunkan kepada Nabi Muhammad SAW dan ditulis didalam mushaf berdasarkan sumber-sumber muttawatir yang bersifat pasti kebenarannya, dan yang dibaca umat Islam dalam rangka ibadah."'(Subhi, 1996)

Al-Qur'an didefinisikan oleh Zakiah Darajat ialah wahyu Allah yang dibukukan, yang diturunkan kepada Nabi Muhammad saw, sebagai suatu mukjizat, membacanya dianggap ibadat, sumber utama ajaran Islam. Menurutnya Pengajian atau pembelajaran al-Qur'an bagi anakanak telah lama membudaya dalam masyarakat Islam. Hanya saja sistem dan caranya perlu diperbaharui dan dikembangkan sesuai dengan perkembangan metode mengajarkan berbagai macam pelajaran. Metode pengajaran al-Qur'an ini perlu diperbaharui dan dikembangkan karena dibutuhkan oleh masyarakat Islam karena mereka ingin dapat membaca al-Qur'an dengan baik dalam waktu yang tidak lama. (Daradjat, 2008)

Definisi-definisi yang dikemukakan oleh para ulama lebih banyak unsur- unsur yang sama dalam mendefinisikan AlQur'an. Dan apabila kita cermati tampak adanya beberapa perbedaan diantara definisi-definisi yang mereka ungkapkan. Akan tetapi perbedaan tersebut tidaklah menjadikan pertentangan dan juga tidak menjadi masalah yang tidak bisa dikompromikan, yang ada justru sebaliknya perbedaan yang ada saling melengkapi pengertian-pengertian yang diungkapkan diantara mereka.

Berdasarkan beberapa pengertian yang diuraikan oleh para ulama, dapat di simpulkan bahwa Al-Qur'an adalah kalam Allah berbahasa Arab yang diturunkan kepada nabi Muhammad melalui malaikat Jibril yang menjadi mu'jizat atas kerasulannya untuk dijadikan petunjuk bagi manusia disampaikan dengan cara muttawattir dalam mushaf dimulai dengan surat Al-fatihah dan diakhiri dengan surat An-Naas serta menjadi ibadah bagi yang membacanya.

Pembelajaran Al-Qur'an sebagai suatu kegiatan interaksi belajar mengajar juga mempunyai tujuan. Adapun tujuan pembelajaran Al-Qur'an sebagaimana diungkapkan oleh prof. Dr. Mahmud Yunus sebagai berikut: "1) agar pelajar dapat membaca Al-Qur'an dengan fasih dan betul menurut tajwid. 2) agar pelajar dapat membiasakan Al-Qur'an dalam kehidupannya. 3) memperkaya 
pembendaharaan kata-kata dan kalimatkalimat yang indah dan menarik hati”.(Mahmud, 1990)

Isi pengajaran al-Qur'an meliputi:

1) Pengenalan Huruf Hijaiyah, dari huruf alif sampai $y a$ '.

2) Cara membunyikan masing-masing huruf hijaiyah dan sifat-sifat huruf itu, yang dibicarakan dalam ilmu Makhraj.

3) Bentuk dan fungsi tanda baca, seperti syakal, syaddah, mad, dan sebagainya

4) Bentuk dan fungsi tanda berhenti baca (waqaf), seperti waqaf muthlaq, waqaf jawaz, dan sebagainya

5) Cara membaca, melagukan dengan bermacam-macam irama dan bermacammacam qiraat yang dimuat dalam Ilmu Qiraat dan Ilmu Nagham.

6) Adabut Tilawah, yang berisi tata cara dan etika membaca al-Qur'an sesuai dengan fungsi bacaan itu sebagai ibadah. (Daradjat, 2008)

\section{b. Metode Membaca Al-Qur'an}

Secara etimologi, istilah metode berasal dari bahasa Yunani "metodos". Kata ini terdiri dari dua suku kata yaitu "metha" yang berarti melalui atau melewati dan "hodos" yang berarti jalan atau cara. (Rasyad, 2003). Dalam Kamus Besar Bahasa Indonesia metode adalah "cara yang teratur dan terpikir baik-baik untuk mencapai maksud"(Depdikbud, 1989). Sehingga dapat diambil kesimpulan bahwa metode adalah suatu cara yang sistematis yang digunakan untuk mencapai tujuan.

Di Indonesia terdapat bermacammacam metode membaca al-Qur'an sebagaimana yang telah dikumpulkan oleh LITBANG pada tahun 1994, diantaranya adalah Metode Baghdadiyyah, Metode Hattaiyyah di Riau, Metode Al-Barqi di Surabaya, Metode Qira'ati di Semarang, Metode Iqra' di Yogyakarta, Metode AlBanjari di Banjarmasin, Metode SAS di Jawa Timur, Metode Tombak Alam di Sumatra Barat, Metode Muhafakah (metode yang digunakan untuk pengajaran
al-Qur'an dengan cara hafalan kalimat sehari-hari), Metode Muqoronah (metode dengan padanan huruf atau persamaan huruf atau Transliterasi), Metode wasilah (Metode urai baca dengan alat peraga), Metode saufiyah (dengan cara gestalt), Metode tarqidiyah, Metode jam'iyah (metode campuran), Metode an-Nur, Metode El-Fath, Metode 15 jam belajar alQur'an, dan Metode $A$ Ba Ta Tsa. (Abdillah, 1996).

Berikut adalah beberapa macam metode membaca Al-Qur'an:

1) Metode Baghdadiyah

Metode Baghdadiyah adalah metode tersusun (tarkibiyah), maksudnya yaitu suatu metode yang tersusun secara berurutan dan merupakan sebuah proses ulang atau lebih kita kenal dengan sebutan metode alif, $b a^{\prime}$, $t a$ '. (Animous, 1414) Menurut pandangan penulis metode ini adalah metode yang paling lama muncul dan metode yang pertama berkembang di Indonesia.

a) Cara mengajarkan Metode Baghdadiyah:

1. Mula-mula diajarkan nama-nama huruf hijaiyah menurut tertib kaidah Baghdadiyah, yaitu dimulai dari huruf alif, $b a^{\prime}, t a^{\prime}$, dan sampai ya'.

2. Kemudian diajarkan tanda-tanda baca (harakat) sekaligus bunyi bacaanya. Dalam hal ini anak dituntun bacanya secara pelanpelan dan diurai/ dieja, seperti alif fathah a, alif kasrah $i$, alif dhammah $u$, dan seterusnya.

3. Setelah anak-anak mempelajari huruf hijaiyah dengan cara-caranya itu, barulah diajarkan kepada mereka al-Qur'an juz'amma (Juz yang ke-30 dari urutan juz dalam al-Qur'an ) itu(Budiyanto, 1995).

b) Kelebihan

Siswa akan mudah dalam belajar karena sebelum diberikan materi sudah hafal huruf-huruf hijaiyah, 
siswa yang lancar akan cepat melanjutkan pada materi selanjutnya karena tidak menunggu orang lain, siswa diperkenalkan nama huruf hijaiyah sejak awal pelajaran(Animous, 1414).

c) Kekurangan

Adapun kekuranganya metode ini menurut penulis, membutuhkan waktu yang lama karena harus menghafal huruf hijaiyah dahulu dan harus dieja sehingga siswa merasa jenuh dan banyak yang tidak menyelesaikan sampai bisa membaca al-Qur'an.

2) Metode Qiro'ati

Metode Qiro'ati adalah pengajaran membaca al-Qurean dengan langsung mempraktekkan bacaan tartil sesuai dengan qa'idah ilmu tajwid, mengajar jilid 1 dan 2 sebaiknya secara perorangan sedangkan mengajar jilid 3 sampai 6 sebaiknya secara klasikal, namun setiap siswa diberi kesempatan membaca(Zarkasi, 1990).

Pada jilid pertama huruf dibaca langsung tanpa mengeja dengan cepat dan tidak memanjangkan suara, pada jilid dua diperkenalkan nama harakat, angka arab, dan bacaan mad thabi'i. Jilid tiga adalah pendalaman jilid satu dan dua, jilid empat dikenalkan nun sukun, tanwin, mad wajib dan mad jaiz, nun dan mim bertasydid, wawu yang tidak dibaca. Jilid lima diajarkan cara waqof, mafatih al suwar dan pendalaman jilid sebelumnya. Pada jilid enam diajarkan cara membaca izhar halqi dan membaca al-Qur'ean juz satu(Zarkasi, 1990).

3) Metode An-Nahdhiyah

Metode an-Nahdhiyah adalah salah satu metode membaca al-Qur'an yang muncul di daerah Tulung agung, Jawa Timur. Materi pembelajaran al-Qur'an tidak jauh berbeda dengan metode Qira'ati dan Iqra' . Dan perlu diketahui bahwa pembelajaran metode ini lebih ditekankan pada kesesuaian dan keteraturan bacaan dengan ketukan atau lebih tepatnya pembelajaran alQur'an pada metode ini lebih menekankan pada kode "ketukan" dalam pelaksanaan.

Inti pelajaran metode an-Nahdhiyah: Pada jilid pertama siswa diperkenalkan huruf yang belum dirangkai sekaligus pengenalan tanda baca fathah, kasrah, dan dhammah. Pada jilid kedua diajarkan rangkaian huruf, bacaan mad thabi'i, tanda bacaan, harakat tanwin, pengenalan angka arab. Jilid yang ketiga diajarkan , ta' marbuthah, huruf dengan tanda sukun, alif Fariqah, ikhfak, hamzah washal. Jilid keempat diajarkan bacaan izhar qomariyah, bacaan izhar syafawi, bacaan izhar halqiyah, dan bacaan mad wajib muttasil. Jilid kelima diajarkan bacaan lien, tanda tasydid, bacaan ghunnah, idhgam bighunnah, idhgam bila ghunnah, dan iqlab, cara membaca lafadz jalalah, dan bacaan ikhfa' syafawi. Di akhir jilid 1-5 diberikan materi do'a harian. Jilid keenam diajarkan idhgam syamsiyah, qolqolah, mad lazim kilmi musaqqol/ mukhaffaf, mad aridly, mad iwadh, mad lazim harfi, tanda-tanda waqof, dan suratsurat pilhan(Ma'arif NU, 1992).

4) Metode Iqra'

Metode Iqra' adalah suatu metode membaca al-Qur'an yang menekankan langsung pada latihan membaca. Adapun buku panduan iqra ${ }^{\text {ee }}$ terdiri dari 6 jilid dimulai dari tingkat yang sederhana, tahap demi tahap sampai pada tingkatan yang sempurna (Humam, 2000).

Pembelajaran membaca al-Qur'an dengan motode Iqra' ini pernah dijadikan proyek oleh Departemen Agama RI sebagai upaya untuk mengembangkan minat baca terhadap kitab suci al-Qur'an. Meski demikian, harus diakui bahwa setiap metode 
memiliki kelebihan dan juga kelemahanya sendiri. Oleh karena itu perlu ada upaya konvergensi dengan memodivikasi beberapa metode guna mendapatkan metode pembelajaran yang menarik, menyenangkan, dan efektif (Roqib, 2009).

a) Sistematika Buku Iqra

Pelajaran di jilid 1 seluruhnya berisi pengenalan bunyi hurufhuruf tunggal berharokat fathah. Diawali dengan huruf $a, b a, t a, t s a$, dan seterusnya sampai bunyi ya. Target yang dicapai anak bisa membaca dan mengucapkan secara fasih sesuai dengan makhrajnya huruf-huruf tunggal berharakat fathah. Dalam hal ini anak belum ditargetkan untuk mengenal namanama huruf itu sendiri, seperti alif, $b a^{\prime}, t a$ ' dan seterusnya.

Jilid 2 diperkenalkan dengan bunyi huruf-huruf bersambung berharakat fathah, baik huruf sambung di awal, di tengah, maupun di akhir kata. Mulai diperkenalkan bacaan "mad" namun masih berharakat. Mulai halaman ini anak boleh diperkenalkan nama huruf demikian pula nama harakat. Target jilid 2 meningkatkan kefasihan membaca bunyi huruf, anak bisa membaca huruf-huruf sambung, anak bisa membedakan bacaan pendek dan panjang dari fathah yang diikuti alif dan fathah berdiri.

Awal jilid 3 ini anak diperkenalkan bacaan kasrah. Karena anak telah mampu membedakan bentukbentuk huruf bersambung, maka pengenalan bacaan kasrah ini langsung huruf tunggal dan huruf sambung sekaligus. Bacaan dhammah dikenalkan pada jilid 3 setelah anak betul-betul mengenal bacaan kasrah dan fathah. Pada halaman 19 langsung diperkenalkan dhammah panjang karena diikuti oleh wawu sukun. Dan disinilah anak dikenalkan huruf wawu dan tanda dhammah, baik dhammah biasa maupun dhammah terbalik sebagai tanda bacaan panjang. Target jilid 3 anak mengenal bacaan kasrah, kasrah panjang karena diikuti ya' sukun dan kasrah pajang karena berdiri, anak mengenal bacaan dhammah, dhammah panjang karena diikuti wawu sukun dan dhammah panjang karena terbalik. Anak sudah mengenal nama tanda baca fathah, kasrah, dhammah dan sukun. Anak sudah mengenal nama-nama huruf alif, ya' dan wawu.

Pelajaran jilid 4 diawali dengan bacaan fathah tanwin, kasrah tanwin, dhammah tanwin, bunyi ya' sukun dan wawu sukun yang jatuh setelah harakat fathah, mim sukun, nun sukun, qolqolah dan huruf hijaiyah lainya yang berharakat sukun, pada jilid ini anak sudah diperkenalkan dengan nama semua huruf hijaiyah dan nama-nama tanda bacanya. Didahulukanya bacaan qolqolah dari huruf-huruf sukun lainya dimaksudkan agar sejak dini anak telah mampu menghayati bacaan qolqolah sehingga terbiasa dengan bacaan yang mestinya berqolqolah tetap dibaca qolqolah. Dalam pelajaran bacaan tanwin, nun sukun dan mim sukun target yang ada pada jilid 4 ini baru memperkenalkan bacaan-bacaan izhar, sedang bacaan yang lain belum diperkenalkan.

Sedangkan dalam jilid 5 diajarkan bacaan alif lam qamariah, tanda waqaf, mad far'i, alif lam syamsyiah, idgham bigunnah, lam jalalah, dan idgam bilagunnah, tetapi belum diperkenalkan istilah- 
istilah yang digunakan dalam ilmu tajwid. Isi jilid 6 sudah memuat semua persoalan-persoalan tajwid, walaupun belum diperkenalkan teori-teori tajwidnya (Budiyanto, 1995).

b) Metode Pembelajaran Iqra'

1. CBSA, siswa aktif membaca sendiri setelah dijelaskan pokok bahasanya, guru hanya menyimak tidak menuntun. Belajar aktif tidak hanya diperlukan untuk menambah gairah, namun juga untuk menghargai perbedaan individual dan keragaman kecerdasan (Silberman, 2004).

2. Privat menyimakan seorang demi seorang secara bergantian. Pendapat Lapp, Bender, Ellenwood \& John di antara model aktivitas belajar adalah The Personilised Model, di mana proses pembelajaran dikembangkan dengan memperhatikan minat, pengalaman dan perkembangan siswa untuk mengaktualisasikan potensi-potensi individualitasnya (Aunurrahman, 2010).

3. Asistensi. Siswa yang lebih tinggi pelajaranya dapat membantu menyimak santri lain. Strategi ini baik digunakan untuk menggairahkan kemauan peserta didik untuk mengajarkan materi kepada temanya. Jika selama ini ada pameo yang mengatakan bahwa metode belajar yang paling baik adalah dengan mengajarkan kepada orang lain, maka strategi ini akan sangat membantu peserta didik dalam mengajarkan kepada teman sekelas (Zaini, dkk., 2008).

c) Kelebihan dan kekurangan

Kelebihan metode Iqra':
1. Adanya buku (modul) yang mudah dibawa dan dilengkapi oleh beberapa petunjuk teknis pembelajaran bagi guru serta pendidikan dan latihan guru agar buku iqra' ini dapat dipahami dengan baik oleh guru, para guru dapat menerapkan metodenya dengan baik dan benar.

2. Cara Belajar siswa aktif (CBSA). siswa diberikan contoh huruf yang telah diberi harakat sebagai pengenalan di lembar awal dan setiap memulai belajar siswa dituntut untuk mengenal huruf hijaiyah tersebut. Pada permulaan, siswa langsung membaca huruf-huruf tersebut secara terpisah-pisah untuk kemudian dilanjutkan ke kata dan kalimat secara gradual. Jika terjadi kesalahan baca, guru memberikan kode agar kesalahan tersebut dibenarkan sendiri dengan cara mengulang bacaan.

3. Bersifat privat (individual). Setiap siswa menghadap guru untuk mendapatkan bimbingan langsung secara individual. Jika pembelajaran terpaksa dilakukan secara kolektif maka guru akan menggunakan buku Iqra' klasikal.

4. Menggunakan sistem asistensi, yaitu santri yang lebih tinggi tingkat pembelajaranya membina siswa yang berada di bawahnya. Meski demikian proses kelulusan tetap ditentukan oleh guru dengan melalui ujian.

5. Guru mengajar dengan pendekatan yang komunikatif, seperti dengan menggunakan bahasa peneguhan saat siswa membaca benar, sehingga siswa 
termotivasi, dan dengan teguran yang menyenangkan jika terjadi kesalahan (Roqib, 2009).

Penulis berpendapat bahwa selain memiliki kelebihan, metode Iqra' juga memiliki kekurangan yaitu :

1. Anak kurang tahu nama huruf hijaiyah karena tidak diperkenalkan dari awal pembelajaran.

2. Anak kurang tahu istilah atau nama-nama bacaan dalam ilmu tajwid.

\section{c. Metode Menulis Al-Qur'an}

Salah satu metode menulis alQur'an adalah dengan cara imla' Menurut Mahmud Ma'ruf (1985:157) Imlak adalah menuliskan huruf-huruf sesuai posisi nya dengan benar dalam kata-kata untuk menjaga terjadinya kesalahan makna. Imlak (Imla'i) adalah katergori menulis yang menekankan pada rupa/postur huruf dalam bentuk kata-kata atau kalimat. Secara umum, ada tiga kecakapan dasar yang dikembangkan dalam keterampilan Imlak, yaitu Kecakapan mengamati, Kecakapan mendengar, dan kelenturan tangan dalam menulis (Abdullah, 2015).

Mengutip dari(Pakcosma, 2015) bahwa Ada 4 (empat) macam jenis imlak yang bisa diterapkan pada seseorang sesuai dengan tahap kognitifnya, yaitu:

1) Imla' manqul: siswa menyalin teks bacaan atau kalimat yang ada di kitab atau tulisan guru di papan ke dalam buku tulis. Imla' jenis ini untuk tingkat pemula, dimana mereka lebih ditekankan untuk cermat dan teliti saat membaca tulisan dan menyalinnya.

2) Imla'mandhur: siswa melihat dan mempelajari teks bacaan atau kalimat yang ada di kitab atau di papan tulis, lalu menutup kitab atau yang ada di papan tulis. Selanjutnya guru mendiktekan tek bacaan atau kalimat yang sama. Imla' mandhur tidak hanya menuntut siswa lebih cermat dan teliti saat membaca, tapi juga harus mengingat bentuk tulisannya dan berkonsentrasi dengan guru. Mata, telinga dan kekuatan daya ingat harus saling mendukung. Imla' mandhur diterapkan dikelas menengah.

3) Imla' ghairu al-mandhur (masmu'): siswa menulis teks bacaan atau kalimat yang dibacakan guru tanpa melihatnya terlebih dahulu (seperti pada metode ke dua). Metode ini untuk tahapan lebih tinggi, di mana siswa telah menguasai dengan baik teori-teori imla' yang telah diajarkan. Ketika siswa mendengarkan bacaan guru, siswa mendeskripsikan (dalam benak) bentuk tulisannya sesuai dengan teori-teori yang ada di memori otaknya, lalu menuliskannya dengan cepat.

4) Imla' ikhtibari: Adalah bentuk imla' yang diberikan kepada siswa yang telah menguasai dan memahami dengan baik teori-teori imla' ikhtibari lebih banyak muatan praktik dari pada muatan teori.

\section{Penutup}

Pembelajaran Al-Qur'an sebagai suatu kegiatan interaksi belajar mengajar juga mempunyai tujuan. Adapun tujuan pembelajaran Al-Qur'an sebagaimana diungkapkan oleh prof. Dr. Mahmud Yunus sebagai berikut: "1) agar pelajar dapat membaca Al-Qur'an dengan fasih dan betul menurut tajwid. 2) agar pelajar dapat membiasakan Al-Qur'an dalam kehidupannya. 3) memperkaya pembendaharaan kata-kata dan kalimatkalimat yang indah dan menarik hati”.

Di Indonesia terdapat bermacammacam metode membaca al-Qur'an. Metode pembelajaran membaca dan menulis al-Qur'an akan terus meningkat dan bertambah dengan adanya berbagai perkembangan pengetahuan masyarakat dan teknologi. Maka sedikit uraian di atas semoga dapat memberi khasanah pengetahuan tentang metode baca alQur'an dan metode penulisannya. Semoga bermanfaat dan meraih ridha-Nya. 
DAFTAR PUSTAKA

Abdillah, H. M. (1996) Ensiklopedia Islam. Jakarta: PT. Iktiar Baru Van Hoeve.

Abdullah, A. 2015, 'adulabdullah Metode-metode menulis dalam pelajaran AL-qur' an Hadits di MI ( andi syaputra, M'.

Animous (1414) Juz'amma. Surakarta: Alwah.

Aunurrahman, 2010, Belajar dan Pembelajaran. Bandung: Alfabeta.

Budiyanto, H. M., 1995, Prinsip-prinsip Metodologi Buku Iqra' (Cara Cepat Belajar Membaca alQur'an). Yogyakarta: AMM.

Daradjat, Z., 2008, Metodik Khusus Pengajaran Agama Islam. Ke-2. Jakarta.

Depdikbud, 1989, Kamus Besar Bahasa Indonesia. Jakarta: Balai pustaka.

Hamalik, O., 1999, Kurikulum dan Pembelajaran. Jakarta: Bumi aksara.

Humam, A., 2000, Buku Iqra' , Cara Cepat Belajar Membaca al-Qur'an, Jilid 1-6. Yogyakarta: AMM.

M.Hasby, A. S., 1997, Sejarah dan pengantar Ilmu Al-Quran dan Tafsir. Cet.1. Semarang: Pustaka Rizki Putra.

Ma'arif NU, L., 1992, Cepat Tanggap Belajar al-Qur'an an-Nahdhiyah. Jilid VI. Tulung Agung: LP. Ma'arif NU.

Mahmud, Y., 1990, Metodik Khusus Pendidikan Agama. Cet.12. Jakarta: Hida Karya agung.

Manna', A.-Q., 2006, Pengantar Studi Ilmu Al-Quran, terj. Mabahits fi 'Ulumil Qur'an. Cet. 1. Edited by R. E.-M. Aunur. Jakarta: Pustaka Al-Kautsar.

Pakcosma (2015) 'Tsurayya ( الثريا ) Pengerian imla', manfaat dan macam-macamnya'.

Rasyad, A., 2003, Teori Belajar dan Pembelajaran. Cet.4. Jakarta:
Uhamka Press.

Roqib, M., 2009, Ilmu Pendidikan Islam (Pengembangan Pendidikan Integratif di Sekolah, keluarga, dan masyarakat). Yogyakarta: LkiS.

Sardiman, A. M., 2008, Interaksi dan Motivasi Belajar Mengajar. Jakarta: Raja Grafindo Persada.

Silberman, M. L. \& A. B., 2004, Active Learning:101 Strategiies to Teach Any Subject, terjemahan Raisul Muttaqien. Bandung: Nusamedia \& Nuansa.

Subhi, A.-S., 1996, Membahas Ilmu-Ilmu Al-Quran. Cet.6. Jakarta: Pustaka Firdausi.

Sudjana, D., 2001, Metode dan Teknik Pembelajaran Partisipatif. Cet.Ke4. Bandung: Falah Production.

Syah, M., 2005, Psikologi Pendidikan Dengan Pendekan Baru. Cet.12. Bandung: Rosda Karya.

Tohirin , 2006, Psikologi Pembelajaran Pendidikan Agama Islam. Jakarta: PT Raja Grafindo Persada.

Wikepedia, 2016, 'Pembelajaran Wikipedia bahasa Indonesia, ensiklopedia bebas', Wikepedia 2016. Available at: https://id.wikipedia.org/wiki/Pembe lajaran.

Zaini, dkk., H., 2008, Strategi Pembelajaran Aktif. Yogyakarta: Pustaka Insan Madani.

Zarkasi, D. S., 1990, Metode Praktis Belajar Membaca al-Qur'an. Semarang: Yayasan Pedidikan alQur'an Mujawwidin. 